\title{
Índice de degradação ambiental em núcleos de desertificação no Nordeste do Brasil
}

\author{
Environmental degradation index in desertification cores in the Northeast of Brazil
}

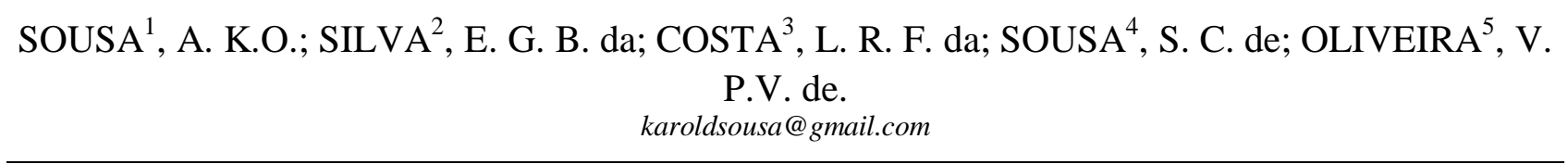

\section{Resumo}

O semiárido do Nordeste brasileiro por apresentar condições naturais favoráveis ao desenvolvimento da agropecuária propiciou desde muito cedo a exploração de seus recursos. Nesse contexto o semiárido foi gradativamente explorado, e isso, associada às condições de semiaridez e a ausência de pousio das terras, contribui para que houvesse um processo lento de regeneração mediante o ritmo acelerado de exploração. Assim, o presente artigo tem como objetivo analisar de forma comparativa o índices de degradação/desertificação de dois núcleos de desertificação: a sub-bacia do riacho Santa Rosa nos município de Jaguaretama e Morada Nova no Ceará e a sub-bacia do riacho Itacuruba/Tamanduá no município de Itacuruba em Pernambuco. A base metodológica gira em torno da análise dos indicadores geobiofísicos de degradação/desertificação elaborado por Oliveira (2011) e aplicados por Costa (2014) e Sousa (2014) nesses dois núcleos respectivamente. Com o resultado das análises pode-se concluir que a sub-bacia cearense apresenta maior área de terras submetidas a nível moderados de degradação/desertificação, cerca de $560 \mathrm{~km}^{2}$ o equivalente a $83,1 \%$ do núcleo. Porém, se consideramos como base o maior nível de degradação, a sub-bacia pernambucana se destaca com nível médio a alto sob uma área de $149,283 \mathrm{~km}^{2}$ o correspondente a $85,28 \%$ desse núcleo.

Palavras-chave: Semiárido. Indicadores Geobiofísicos. Degradação/Desertificação.

\begin{abstract}
The semiarid region of northeastern Brazil because of its natural conditions favorable to the development of agriculture led very early exploitation of its resources. In this context the semiarid region was gradually explored, and this, combined with the semiaridez conditions and the absence of fallow land, contributes to that there was a slow regeneration process by the fast pace of exploration. Thus, this article aims to analyze comparatively the rates of degradation / desertification two centers of desertification: the sub-basin of the creek Santa Rosa in the municipality of Jaguaretama and Morada Nova Ceará and stream sub-basin Itacuruba / anteater in Itacuruba municipality in Pernambuco. The methodological basis revolves around the analysis of geobiofísicos indicators of degradation / desertification prepared by Oliveira (2011) and applied by Costa (2014) and Sousa (2014) these two cores respectively. With the test results it can be concluded that the cearense sub-basin has higher land area subjected to moderate level of degradation / desertification about $560 \mathrm{~km}^{2}$ equivalent to $83.1 \%$ of the core. However, if we take as a basis the highest level of degradation, Pernambuco sub-basin stands with medium to high level in an area of $149,283 \mathrm{~km}^{2}$ corresponding to $85.28 \%$ of the core.
\end{abstract}

Keywords: Semiarid. Geobiofísicos Indicators. Degradation / Desertification.

\section{INTRODUÇÃO}

O semiárido do Nordeste brasileiro foi desde muito cedo submetido à exploração de seus recursos naturais por meio da atividade da pecuária, onde a abertura de novas vias de colonização significava na prática a expansão de fazendas de gado.

\footnotetext{
${ }^{1}$ Ana Karolina de Oliveira Sousa,

${ }^{2}$ Msc. Érika Gomes Brito da Silva,

${ }^{3}$ Msc. Luis Ricardo Fernandes da Costa,

${ }^{4}$ Dr. Sebastião Cavalcante de Sousa,

${ }^{5}$ Dra. Vládia Pinto Vidal de Oliveira, ${ }^{1,2,3,4,5}$ Departamento de Geografia / Laboratório de Pedologia Análise Ambiental e 
Essa atividade caracterizou o uso e a ocupação inicial do interior do território nordestino, sendo o principal ciclo econômico até os fins do século XVIII, com destaques para a comercialização do couro e da carne seca, produtos estes que ficaram conhecidos por civilização do couro e as charqueadas, respectivamente.

Com o declínio das charqueadas, em seguida, a cotonicultura tornou-se a atividade responsável pelo desenvolvimento econômico na região até meados do século XX. Assim, o binômio gadoalgodão gerou riquezas para grandes proprietários de terras. Em contrapartida, graves problemas ambientais foram desencadeados e o semiárido foi sendo gradativamente explorado, havendo, portanto, a substituição da cobertura vegetal natural por pastos e pela agricultura de subsistência.

Dentre as cultivadas, o algodão foi o vetor principal do desmatamento, como destaca Guerra; Souza; Lustosa (2012, p. 107) sobre o processo inicial de devastação das caatingas em um dos cenários de degradação ambiental no Ceará, o Sertão do Jaguaribe, cujo foi dado "por meio da abertura de clareiras para o assentamento do gado e, posteriormente, efetivas varreduras na vegetação nativa após a introdução dos algodoais".

Associa-se ainda às condições de semiaridez acentuada pelos sucessivos períodos de secas, o que contribuiu para um processo lento de regeneração do ambiente mediante o ritmo acelerado de exploração vivenciado desde o período colonial.

Atualmente, outras atividades vêm sendo desenvolvidas, incrementando esse contexto de degradação. A caprinocultura e a ovinocultura são exemplos de animais de menor porte que tem ganhado cada vez mais espaço na atividade da pecuária, chegando o número do rebanho a equiparar-se ao do gado bovino (PERNAMBUCO, 2009).

No sertão cearense, já se nota a gradativa substituição da bovinocultura de corte por estes rebanhos (CEARÁ, 2010). Isso se deve a melhor adaptação desses animais as condições limitadas de recursos hídricos e forrageiros, trazendo de certo modo, maiores rentabilidades aos produtores.

Há também o extrativismo e o investimento no plantio de outras cultivares. Em Pernambuco, a mamona e o agave vieram a configurar a prática do "sistema de cultivo misto com dupla vocação: produzir alimentos para consumo e produtos com fins comerciais” (PERNAMBUCO, op cit). Porém, tais sistemas nunca vieram a substituir a pecuária baseada na criação do gado bovino, pelo contrário, estiveram sempre conjugados a este sistema de produção (PERNAMBUCO, op cit).

A ausência de pousio principalmente das terras situadas em torno das bacias hidrográficas - as quais se constituíam em vias naturais de acesso para o interior do território e posteriormente para o escoamento da produção para o litoral, sendo, portanto, os primeiros espaços povoados e consequentemente explorados - são onde atualmente se encontram as principais áreas degradadas, enquadradas como núcleos de desertificação. 
Daí a importância de estudos voltados para a problemática da degradação/desertificação baseadas em metodologias que viabilizem diagnosticar e quali-quantificar os elementos e processos formadores desses sistemas ambientais para melhor compreender suas dinâmicas naturais e suas mudanças frente às intervenções humanas as quais estão submetidos.

Matallo Junior (2001) faz um panorama histórico da metodologia baseada em indicadores para o estudo da desertificação. Segundo ele, as tentativas realizadas para definir e sistematizar uma metodologia geral, dado a heterogeneidade das regiões semiáridas e aos numerosos critérios a ser considerados, ainda é um desafio, pois requer um tratamento sistêmico dos dados, e isso nem sempre acontece.

Na tentativa de desenvolver metodologias minimamente padronizadas, foi realizada em 1994, na cidade de Fortaleza estado do Ceará, a Conferência Nacional e Seminário Latino-Americano da Desertificação (CONSLAD) que reuniu pesquisadores pra debater estratégias metodológicas que possibilitassem realização diagnóstica e comparação dessa problemática ambiental em diferentes áreas.

Dentre os trabalhos desenvolvidos no Brasil, temos o de Vasconcellos Sobrinho (1971 apud MATALLO JUNIOR, 2001), que pela primeira vez adotou núcleos de desertificação como critério de análise espacial na área compreendida pelo polígono da secas no semiárido nordestino.

Os núcleos são áreas representativas de máximo processo de degradação, uma vez que mediante a impossibilidade de se trabalhar vastas áreas de forma aprofundada, os mesmo "devem ser considerados como as 'unidades mínimas' a partir das quais os estudos devem ser conduzidos." (VASCONCELLOS SOBRINHO, 1971,1983 apud MATALLO JUNIOR, 2001, p. 51).

Nessa perspectiva temos os trabalhos desenvolvidos por Oliveira $(2011,2012)$, que padronizou seis critérios de análise para compreender a atual dinâmica dos sistemas ambientais na ilha de Santiago-Cabo Verde, frente aos problemas de degradação/desertificação. Tal sistematização permitiu que fossem realizadas outras aplicações, só que em território brasileiro, fato este que vem possibilitando pesquisas voltadas para a comparação da degradação entre essas áreas.

Nesse contexto, o presente artigo vem destacar a realidade de dois núcleos de desertificação no Ceará e Pernambuco, tendo como recorte espacial áreas de bacias hidrográficas. O primeiro núcleo, localizados no Ceará, é o do Sertão do Médio Jaguaribe, compreendido pela sub-bacia do Riacho Santa Rosa localizada na porção centro-norte do estado. Abrange parte dos municípios de Morada Nova e Jaguaretama, entre as coordenadas $5^{\circ} 27^{\prime} \mathrm{S}$ e $5^{\circ} 12^{\prime} \mathrm{S}$ e $38^{\circ} 55^{\prime} \mathrm{W}$ e $38^{\circ} 17^{\prime} \mathrm{W}$, com uma área de aproximadamente $675 \mathrm{Km}^{2}$ (COSTA, 2014).

O segundo núcleo fica em Pernambuco no município de Itacuruba. Corresponde a sub-bacia do riacho Itacuruba /Tamanduá, um afluente do Rio São Francisco. Está localizado no sertão central do 
estado, entre as coordenadas geográficas $08^{\circ} 43^{\prime} 47,5^{\prime \prime} \mathrm{S}$ e $08^{\circ} 48^{\prime} 07,8^{\prime \prime}$ S e $38^{\circ} 40^{\prime} 54,3^{\prime \prime}$ W e $38^{\circ}$ 43' 38, 1" W com área de 175,066 Km² (SOUSA, 2014).

$\mathrm{O}$ artigo objetiva analisar de forma comparativa o índice de degradação/desertificação dos dois núcleos, a partir de indicadores geobiofísicos. Com base nessas análises, acredita-se obter conhecimentos mais consistentes que venham posteriormente contribuir na elaboração de prognósticos que subsidiem planos de ação mais coerentes com a realidade do semiárido.

\section{METODOLOGIA}

$\mathrm{O}$ artigo tem como base metodológica de análise os indicadores geobiofísicos aplicados em cenários de degradação/desertificação no semiárido cearense e pernambucano por Costa (2014) e Sousa (2014) respectivamente.

Tais indicadores - aqui denominados de geobiofísicos por considerar o termo mais pertinente aos critérios utilizados - foram desenvolvidos por Oliveira $(2011,2012)$ para analisar os índices de degradação ambiental dos sistemas ambientais na Ilha de Santiago - Cabo Verde.

Assim, foram considerados seis critérios geobiofísicos: geologia, geomorfologia, cobertura vegetal, solos (espessura), solos (erosão) e setorização bioclimática, com variações de degradação de 1 a 5 (ver quadro 1), onde os maiores valores correspondem na maior capacidade de suporte do ambiente e menor índice de degradação/desertificação.

Quadro 1- Indicadores geobiofísicos de degradação/desertificação - IGBD. Fonte: Oliveira, 2011; Costa 2014, Sousa, 2014.

\begin{tabular}{|c|c|c|c|c|c|}
\hline Indicador & Valor Original & $\begin{array}{c}\text { Valor } \\
\text { Transformado } \\
\end{array}$ & Indicador & Valor Original & $\begin{array}{c}\text { Valor } \\
\text { Transformado }\end{array}$ \\
\hline \multicolumn{3}{|c|}{ Geologia (Litotipos /permeabilidade) (IGBD1) } & \multicolumn{3}{|c|}{ Solos (espessura) (IGBD4) } \\
\hline Depósitos Sedimentares & --- & 5 & Muito profundo & $>200 \mathrm{~cm}$ & 5 \\
\hline Rochas sedimentares & ---- & 4 & Profundo & $100 \mathrm{a} 200 \mathrm{~cm}$ & 4 \\
\hline Rochas Vulcânicas & ---- & 3 & Moderadamente rasos & 50 a $100 \mathrm{~cm}$ & 3 \\
\hline Rochas metamórficas & ---- & 2 & Raso & 25 a $50 \mathrm{~cm}$ & 2 \\
\hline Rochas ígneas & ---- & 1 & Muito raso com afloramentos rochosos & Sem solo $<25 \mathrm{~cm}$ & 1 \\
\hline \multicolumn{3}{|c|}{ Geomorfologia (Declividade/Topográfica) (IGBD2) } & \multicolumn{3}{|c|}{ Solos (erosão) (IGBD5) } \\
\hline Plano & $0-3 \%$ & 5 & Não aparente & 0 a $15 \%$ & 5 \\
\hline Suave Ondulado & $3-8 \%$ & 4 & Laminar (ligeira) & 15 a $30 \%$ & 4 \\
\hline Ondulado & $8-15 \%$ & 3 & Laminar (moderada a forte) & 30 a $40 \%$ & 3 \\
\hline Fortemente Ondulado & $15-45 \%$ & 2 & Sulcos & 45 a $60 \%$ & 2 \\
\hline Montanhoso & $>45 \%$ & 1 & Voçorocas & $>60 \%$ & 1 \\
\hline \multicolumn{3}{|c|}{ Cobertura Vegetal (Percentual de Ocupação) (IGBD3) } & \multicolumn{3}{|c|}{ Setorização Bioclimática (IGBD6) } \\
\hline Alto & $>75 \%$ & 5 & Super-úmido & ---- & 5 \\
\hline Médio-alto & $54-75 \%$ & 4 & Úmido & ---- & 4 \\
\hline Médio & $32-53 \%$ & 3 & Subúmido seco & ---- & 3 \\
\hline Médio-baixo & $10-31 \%$ & 2 & Semiárido & $\begin{array}{c}--- \\
--\end{array}$ & 2 \\
\hline Inferior a $10 \%$ & $<10 \%$ & 1 & Árido & ---- & 1 \\
\hline
\end{tabular}

Sousa; Sousa; Bezerra e Oliveira (2015) distribuíram os índices de degradação em cinco níveis, como mostra o quadro abaixo.

Quadro 2 - Níveis de degradação/desertificação. Fonte: SOUSA; SOUSA; BEZERRA, OLIVEIRA (2015).

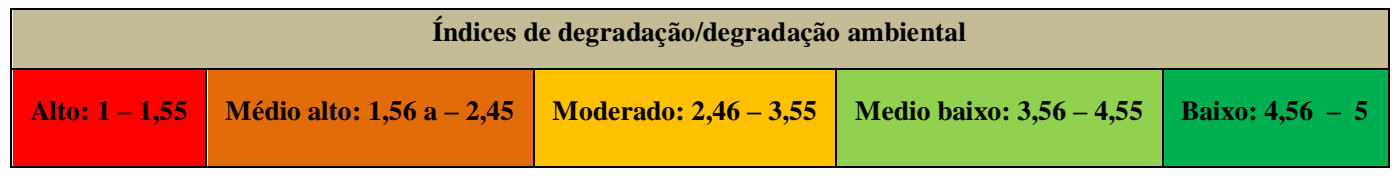


A partir de dados bibliográficos (tese, dissertação, artigo - Sousa, 2014; Costa, 2014; Oliveira, 2011 e 2012) foram feito a caraterização dos sistemas ambientais presentes em cada um dos núcleos: Depressão sertaneja aplainada; Depressão sertaneja parcialmente dissecada; Cristas residuais e inselbergs; Tabuleiros interiores e Planícies fluviais. Tais sistemas constituem nos critérios de delimitação espacial para aplicação dos indicadores e de suas respectivas análises.

\section{RESULTADOS E DISCUSSÃO}

Os núcleos de acordo com os estudos de Vasconcelos Sobrinho (2002 apud PERNANBUCO, 2009), estão enquadrados em duas das seis as áreas piloto de investigação sobre desertificação no semiárido brasileiro, sendo o primeiro no sertão dos Inhamuns no Ceará, e o segundo no Sertão Central de Pernambuco.

Tal fato corrobora para a necessidade de intervenções nessas áreas, as quais tem como ponto de partida a busca de conhecimentos sobre as dinâmicas naturais e suas reais capacidades de suportes mediante as intervenções humanas.

Nesse contexto, os quadros a seguir trazem uma síntese das características naturais associadas com as principais intervenções humanas e problemáticas ambientais por elas acarretadas. O quadro 3 apresenta os sistemas ambientais no núcleo da sub-bacia do riacho Santa Rosa, no sertão do médio Jaguaribe. Os dados revelam que a área se encontra em condições socioambientais predispostos aos processos de desertificação.

O sistema ambiental da depressão sertaneja aplainada, o segundo maior sistema da sub-bacia distribuído em uma área de 234,9 km², apresentou nível moderado de degradação/desertificação com índice de 2,83. Analisando seus elementos geobiofísicos, pode-se compreender que o sistema é caracterizado por um relevo de rochas metamórficas, com declividade suave ondulado de 3-8\%.

A cobertura vegetal tida como um bio-indicador de degradação, apresentou valores entre médio a baixo o que compreende em 10 a $31 \%$ de área coberta. Apesar de não ser uma densidade considerável, observa-se esta cobertura associada com a disposição do modelado do relevo vem a contribuir para que não haja um escoamento superficial intenso, mas apenas erosão laminar ligeira em torno de 15 a $30 \%$ da área total do sistema. Isso vai se refletir também na moderada erosão dos solos, os quais possuem de 50 a $100 \mathrm{~cm}$ de profundidade.

A depressão sertaneja dissecada apresentou índice 3, também nível moderado de degradação/desertificação. É o sistema de maior expressividade com $293 \mathrm{~km}^{2}$ o equivalente a 43,4\% da sub-bacia. A geologia constituída por rochas metamórficas do pré-cambriano associado com o modelado geomorfológico ondulado com cerca de $8-15 \%$ de declividade o que dificulta a infiltração hídrica. Em contrapartida, a cobertura vegetal está com níveis médio-alto o que 
representa cerca de $54-75 \%$. A erosão laminar pode ser considerada um dos fatores responsáveis por manter solos moderadamente rasos.

Quadro 3- Sistemas ambientais e índices de degradação do núcleo de desertificação do Sertão do Médio Jaguaribe. Fonte: Costa (2014). Adaptado por SOUSA; SOUSA; BEZERRA; OLIVEIRA, 2015.

\begin{tabular}{|c|c|c|c|c|c|c|c|c|c|c|c|c|c|c|}
\hline $\begin{array}{c}\text { Sistemas } \\
\text { ambientais }\end{array}$ & $\begin{array}{c}\text { Geologia e } \\
\text { Geomorfologia }\end{array}$ & Solo & Vegetação & & & $\begin{array}{l}\text { Idore } \\
\text { De } \\
\text { sertif } \\
3\end{array}$ & $\begin{array}{l}\text { es Ge } \\
\text { grad } \\
\text { ficaçá } \\
4\end{array}$ & $\begin{array}{l}\text { ação } \\
\text { ão - I } \\
5\end{array}$ & $\begin{array}{l}\text { físico } \\
\text { I } \\
\text { IGBI } \\
6 \\
\end{array}$ & $\begin{array}{l}\text { os de } \\
\text { D } \\
\text { Índice }\end{array}$ & Atividades & Problemas ambientais & $\begin{array}{l}\text { Área } \\
\text { km² }^{2}\end{array}$ & $\%$ \\
\hline $\begin{array}{l}\text { Depressão } \\
\text { sertaneja } \\
\text { aplainada }\end{array}$ & $\begin{array}{c}\text { Depressão Sertaneja } \\
\text { esculpida em rochas } \\
\text { metamórficas do Pré- } \\
\text { Cambriano representa- } \\
\text { das pelo Complexo } \\
\text { Jaguaretama e gra- } \\
\text { níticas da suíte grani- } \\
\text { toide itaporanga. Su- } \\
\text { perfície aplainada por } \\
\text { processos de pedi- } \\
\text { planação, com caimen- } \\
\text { to topográfico para os } \\
\text { fundos de vale. Os ní- } \\
\text { veis altimétricos vari- } \\
\text { am de } 60 \text { a } 140 \text { metros. }\end{array}$ & $\begin{array}{c}\text { Associação } \\
\text { dos } \\
\text { Neossolos } \\
\text { Litólicos e } \\
\text { Planossolos. }\end{array}$ & $\begin{array}{c}\text { Caatinga } \\
\text { arbustiva } \\
\text { aberta } \\
\text { degradada. }\end{array}$ & 2 & 4 & 2 & 3 & 4 & 2 & 2,83 & $\begin{array}{l}\text { Pecuária } \\
\text { extensiva } \\
\text { e } \\
\text { agricultura } \\
\text { irrigada. }\end{array}$ & $\begin{array}{l}\text { Vegetação degrada com } \\
\text { baixa diversidade } \\
\text { florística; a atividade de } \\
\text { sobrepastoreio tem } \\
\text { provocado ramoneamento } \\
\text { das cascas das árvores, } \\
\text { dos brotos em germinação } \\
\text { nos ramos e nas plântulas } \\
\text { acarretando o nanonismo, } \\
\text { morte e aumento dos } \\
\text { espaçamento entre os } \\
\text { indivíduos; solos } \\
\text { erodidos; superfície com } \\
\text { cerca de } 15 \% \text { a } 50 \% \text { de } \\
\text { pedregosidade. }\end{array}$ & 234,9 & 34,8 \\
\hline $\begin{array}{l}\text { Depressão } \\
\text { sertaneja } \\
\text { parcial- } \\
\text { mente } \\
\text { dissecada }\end{array}$ & $\begin{array}{c}\text { Depressão Sertaneja } \\
\text { com predominância de } \\
\text { rochas metamórficas } \\
\text { do Pré-Cambriano } \\
\text { representadas pelo } \\
\text { Complexo } \\
\text { Jaguaretama. } \\
\text { Superfície } \\
\text { moderadamente } \\
\text { dissecada, com } \\
\text { ocorrência de sulcos de } \\
\text { erosão nas áreas de } \\
\text { maior declividade. Os } \\
\text { níveis altimétricos } \\
\text { variam de } 140 \text { a } 240 \\
\text { metros. } \\
\text { Ambiente de transição } \\
\text { com tendência à } \\
\text { instabilidade. }\end{array}$ & $\begin{array}{l}\text { Associação } \\
\text { de: } \\
\text { Neossolos } \\
\text { Litólicos, } \\
\text { Planossolos, } \\
\text { Luvissolos, } \\
\text { Neossolos } \\
\text { Regolíticos } \\
\text { e Argissolo } \\
\text { Vermelho- } \\
\text { Amarelo } \\
\text { Eutrófico. }\end{array}$ & $\begin{array}{l}\text { Caatinga } \\
\text { arbustiva } \\
\text { densa e } \\
\text { aberta } \\
\text { degradada. }\end{array}$ & 2 & 3 & 4 & 3 & 4 & 2 & 3 & $\begin{array}{l}\text { Pecuária } \\
\text { extensiva. }\end{array}$ & $\begin{array}{l}\text { Vegetação degradada; A } \\
\text { atividade de } \\
\text { sobrepastoreio tem } \\
\text { provocado ramoneamento } \\
\text { das cascas das árvores, } \\
\text { dos brotos em germinação } \\
\text { nos ramos e nas plântulas } \\
\text { acarretando o nanonismo, } \\
\text { morte e aumento dos } \\
\text { espaçamento entre os } \\
\text { indivíduos; solos erodido } \\
\text { com pedregosidade. }\end{array}$ & 293 & 43,4 \\
\hline $\begin{array}{l}\text { Cristas } \\
\text { residuais }\end{array}$ & $\begin{array}{l}\text { Superfície dissecada, } \\
\text { resultante dos } \\
\text { processos de erosão } \\
\text { diferencial. } \\
\text { Os níveis altimétricos } \\
\text { nessas áreas estão em } \\
\text { torno } 240 \text { metros. } \\
\text { Ambientes } \\
\text { considerados instáveis. }\end{array}$ & $\begin{array}{l}\text { Ocorrência } \\
\text { de } \\
\text { afloramentos } \\
\text { rochosos } \\
\text { associados } \\
\text { aos } \\
\text { Neossolos } \\
\text { Litólicos. }\end{array}$ & $\begin{array}{l}\text { Caatinga } \\
\text { arbustiva } \\
\text { aberta. }\end{array}$ & 2 & 2 & 1 & 1 & 5 & 2 & 2,16 & $\begin{array}{l}\text { Pecuária } \\
\text { extensiva. }\end{array}$ & $\begin{array}{l}\text { Vegetação degrada; a } \\
\text { atividade de } \\
\text { sobrepastoreio tem } \\
\text { provocado ramoneamento } \\
\text { das cascas dasárvores, dos } \\
\text { brotos em germinação nos } \\
\text { ramos e nas plântulas } \\
\text { acarretando o nanonismo, } \\
\text { morte e aumento dos } \\
\text { espaçamento entre os } \\
\text { indivíduos; pedregosidade } \\
\text { sobressai na paisagem } \\
\text { variando de } 50 \% \text { a } 100 \% \text {. }\end{array}$ & 5,9 & 0.8 \\
\hline $\begin{array}{l}\text { Planícies } \\
\text { fluviais }\end{array}$ & $\begin{array}{l}\text { Áreas onde prepondera } \\
\text { o acúmulo de } \\
\text { sedimentos aluviais do } \\
\text { quaternário. São áreas } \\
\text { com topografia mais } \\
\text { rebaixada. Ambiente } \\
\text { de transição com } \\
\text { tendência a } \\
\text { instabilidade. }\end{array}$ & $\begin{array}{c}\text { Associação } \\
\text { de } \\
\text { Neossolos } \\
\text { Flúvicos e } \\
\text { Planossolos } \\
\text { com } \\
\text { fertilidade } \\
\text { média } \\
\text { natural à } \\
\text { alta. } \\
\end{array}$ & $\begin{array}{l}\text { Matas } \\
\text { ciliares de } \\
\text { carnaubais } \\
\text { (Copernicia } \\
\text { prunifera) } \\
\text { degradada. }\end{array}$ & 5 & 4 & 3 & 4 & 4 & 2 & 3,66 & $\begin{array}{c}\text { Área } \\
\text { preservada. }\end{array}$ & Não discriminado & 86,8 & 13 \\
\hline $\begin{array}{l}\text { Tabuleiros } \\
\text { interiores. }\end{array}$ & $\begin{array}{c}\text { Superfície plana e } \\
\text { suave ondulada, } \\
\text { composta de } \\
\text { sedimentos argilo- } \\
\text { arenosos e areno- } \\
\text { argilosos do } \\
\text { Cenozoico (Tércio- } \\
\text { quaternário). Os níveis } \\
\text { altimétricos variam de } \\
80 \text { a } 120 \text { metros. } \\
\text { Ambiente estável com } \\
\text { tendência à } \\
\text { instabilidade. } \\
\end{array}$ & $\begin{array}{l}\text { Argissolo } \\
\text { Vermelho- } \\
\text { Amarelo } \\
\text { Distrófico } \\
\text { com } \\
\text { fertilidade } \\
\text { natural } \\
\text { média a } \\
\text { baixa. }\end{array}$ & $\begin{array}{l}\text { Caatinga } \\
\text { arbustiva } \\
\text { arbórea e } \\
\text { vegetação } \\
\text { de tabuleiro } \\
\text { degradada, } \\
\text { onde se } \\
\text { destaca a } \\
\text { espécie } \\
\text { Anacardium } \\
\text { occidentale } \\
\text { (cajueiro). }\end{array}$ & 4 & 5 & 2 & 5 & 3 & 2 & 3,50 & $\begin{array}{l}\text { Pecuária e o } \\
\text { extrativismo } \\
\text { vegetal. }\end{array}$ & $\begin{array}{l}\text { Alta descaracterização da } \\
\text { vegetação subcaducifólia } \\
\text { de tabuleiro; riscos de } \\
\text { poluição dos recursos } \\
\text { hídricos; mineração } \\
\text { descontrolada. }\end{array}$ & 33,5 & 4.9 \\
\hline \multicolumn{13}{|c|}{ Área total } & 654.1 & $\begin{array}{c}96.9 \\
\text { Valor de } \\
3.1 \text { não } \\
\text { discriminado }\end{array}$ \\
\hline
\end{tabular}


Já as cristas residuais teve índice de 2,16 se enquadrando no nível médio alto de degradação/desertificação, porém só representa $0.8 \%$ do núcleo com $5,9 \mathrm{~km}^{2}$. As rochas nesse sistema são metamórficas com relevo fortemente ondulado, onde a declividade chega a ser de 1545\%. O que mais acentua a degradação/desertificação nesse sistema é ausência da cobertura vegetal, cuja possui valores inferiores a 10\%. Os solos chegam ao máximo de $25 \mathrm{~cm}$ de profundidade com destaques para os afloramentos rochosos.

Os sistemas de planícies fluviais apresentou índice de 3,66, valor este considerado médio-baixo. É um ambiente constituído por depósito sedimentar e relevo suave ondulado com média de 3 -8\% de declividade. A cobertura vegetal apresenta uma porcentagem média, em torno de $32-53 \%$. Os solos são profundos com cerca de100 a $200 \mathrm{~cm}$. Dado a tipologia geológica e a baixa declividade do relevo, o que favorece o processo de infiltração em detrimento do escoamento superficial, a erosão foi classificada como não aparente.

Dentre os sistemas ambientais as planícies fluviais são as únicas que apresentam maior potencialidade ambiental e menor vulnerabilidade. Isso deve-se ao fato de se constituir atualmente em uma área de preservação. Associado a essa condição, há também de se considerar as características naturais que atribuem a esse sistema uma maior resiliência quando submetido a condições de pousio. Porém, em termos de expressividade ambiental, as planícies só representam $13 \%$ da área total, o equivalente a $86,8 \mathrm{~km}^{2}$.

Os Tabuleiros interiores com área de $33,5 \mathrm{~km}^{2}$ o correspondente a 4,9\% do núcleo, apresentou um índice moderado de degradação/desertificação de 3,50. A estrutura geológica é composta por rochas sedimentares dispostos em um relevo plano com declividade variando de $0-3 \%$. A cobertura vegetal apresenta-se bastante degrada com valores de 10-31\%.

Os solos são classificados como muito profundo onde a espessura é igual à superior $200 \mathrm{~cm}$. Apesar de ser um relevo plano em rochas sedimentares a erosão é laminar com característica de moderada a forte. Isso se deve à ausência da cobertura vegetal, pois uma vez retirada, os solos ficam desnudos e susceptíveis ao processo de erosão.

O quadro 4 faz referência aos sistemas ambientais com seus diferentes usos, ocupações e problemas ambientais do núcleo de desertificação de Itacuruba. Ao analisar cada um de seus sistemas ambientais, pode-se constatar para a depressão sertaneja aplainada apresenta um índice de 3,5 o que indica que a degradação/desertificação está em nível moderado.

A mesma está distribuída em uma área de $23,536 \mathrm{~km}^{2}$, referente a $13,44 \%$ do núcleo. Possui uma estrutura geológica compostos por rochas metamórficas em formas de relevo suave ondulado com declividade de $3-8 \%$. Consta uma cobertura vegetal inferior a $10 \%$, sob solos moderadamente rasos 
com espessuras de 50 a $100 \mathrm{~cm}$. A erosão foi diagnosticada como não aparente, apontando valores de apenas 0 a 15\% da área compreendida pelo sistema. A baixa declividade do relevo é considerado um dos fatores que justifica essa baixa erodibilidade.

Quadro 4- Sistemas ambientais e índices de degradação do núcleo de desertificação de Itacuruba. Fonte: Sousa (2014). Adaptado por SOUSA; SOUSA; BEZERRA; OLIVEIRA, 2015.

\begin{tabular}{|c|c|c|c|c|c|c|c|c|c|c|c|c|c|c|}
\hline $\begin{array}{c}\text { Sistemas } \\
\text { ambientais }\end{array}$ & $\begin{array}{c}\text { Geologia e } \\
\text { Geomorfologia }\end{array}$ & Solo & Vegetação & \multicolumn{7}{|c|}{$\begin{array}{c}\text { Indicadores Geobiofísicos de } \\
\text { Degradação/ } \\
\text { desertificação - IGBD }\end{array}$} & Atividades & Problemas ambientais & $\begin{array}{l}\text { Área } \\
\mathbf{k m}^{2}\end{array}$ & $\%$ \\
\hline $\begin{array}{l}\text { Depressão } \\
\text { sertaneja } \\
\text { aplainada }\end{array}$ & $\begin{array}{l}\text { Superfícies } \\
\text { pediplanadas com } \\
\text { embasamento de } \\
\text { rochas do Pré- } \\
\text { Cambriano } \\
\text { (gneisses grani- } \\
\text { ticos, biotita- } \\
\text { gnaisse, grano- } \\
\text { diorito-gnaisse, } \\
\text { migmatitos) e de } \\
\text { relevo plano e } \\
\text { suave-ondulado. } \\
\text { Ambiente de } \\
\text { baixa } \\
\text { instabilidade. }\end{array}$ & $\begin{array}{l}\text { Neossolo } \\
\text { Litólico } \\
\text { Neossolo } \\
\text { Regolítico. }\end{array}$ & $\begin{array}{l}\text { Caatinga } \\
\text { arbustiva } \\
\text { aberta e } \\
\text { degradada. }\end{array}$ & 2 & 4 & 1 & 3 & 5 & 2 & 3,5 & $\begin{array}{l}\text { Pecuária } \\
\text { extensiva e } \\
\text { agricultura } \\
\text { irrigada. }\end{array}$ & $\begin{array}{c}\text { Vegetação degrada } \\
\text { com baixa diversidade } \\
\text { florística; a atividade } \\
\text { de sobrepastoreio tem } \\
\text { provocado } \\
\text { ramoneamento das } \\
\text { cascas das árvores, dos } \\
\text { brotos em germinação } \\
\text { nos ramos e nas } \\
\text { plântulas acarretando o } \\
\text { nanonismo, morte e } \\
\text { aumento dos } \\
\text { espaçamento entre os } \\
\text { indivíduos; solos } \\
\text { erodidos; superfície } \\
\text { com cerca de } 15 \% \text { a } \\
50 \% \text { de pedregosidade. }\end{array}$ & $\begin{array}{c}23,53 \\
6\end{array}$ & 13.44 \\
\hline $\begin{array}{l}\text { Depressão } \\
\text { sertaneja } \\
\text { parcialmente } \\
\text { dissecada }\end{array}$ & $\begin{array}{l}\text { Superfície de } \\
\text { erosão, com } \\
\text { embasamento de } \\
\text { rochas do Pré- } \\
\text { Cambriano } \\
\text { (gneisses grani- } \\
\text { ticos, biotita- } \\
\text { gnaisse, grano- } \\
\text { diorito-gnaisse, } \\
\text { migmatitos) e } \\
\text { relevo ondulado. } \\
\text { Ambiente de } \\
\text { transição } \\
\text { tendendo à } \\
\text { instabilidade. } \\
\end{array}$ & $\begin{array}{l}\text { Luvissolo, } \\
\text { Neossolo } \\
\text { Litólico. }\end{array}$ & $\begin{array}{c}\text { Caatinga } \\
\text { arbustiva } \\
\text { aberta } \\
\text { degradada. }\end{array}$ & 2 & 3 & 1 & 3 & 3 & 2 & 2,3 & $\begin{array}{l}\text { Pecuária } \\
\text { extensiva. }\end{array}$ & $\begin{array}{l}\text { Vegetação degradada; } \\
\text { A atividade de } \\
\text { sobrepastoreio tem } \\
\text { provocado } \\
\text { ramoneamento das } \\
\text { cascas das árvores, dos } \\
\text { brotos em germinação } \\
\text { nos ramos e nas } \\
\text { plântulas acarretando o } \\
\text { nanonismo, morte e } \\
\text { aumento dos } \\
\text { espaçamento entre os } \\
\text { indivíduos; os solos } \\
\text { apresentam-se erodidos } \\
\text { com pedregosidade. }\end{array}$ & $\begin{array}{c}147,5 \\
65\end{array}$ & 84,29 \\
\hline $\begin{array}{c}\text { Cristas } \\
\text { residuais. }\end{array}$ & $\begin{array}{l}\text { Relevo dissecado } \\
\text { com interflúvios } \\
\text { culminando em } \\
\text { cristas, rochas do } \\
\text { Pré-Cambriano } \\
\text { (gneisses grani- } \\
\text { ticos, biotita- } \\
\text { gnaisse, grano- } \\
\text { diorito-gnaisse, } \\
\text { migmatitos) } \\
\text { relevo forte } \\
\text { ondulado a } \\
\text { montanhoso. } \\
\text { Ambiente de } \\
\text { transição } \\
\text { tendendo à } \\
\text { instabilidade. }\end{array}$ & $\begin{array}{l}\text { Neossolo } \\
\text { Litólico. }\end{array}$ & $\begin{array}{c}\text { Caatinga } \\
\text { arbustiva } \\
\text { aberta e } \\
\text { degradada }\end{array}$ & 2 & 1 & 1 & 2 & 4 & 2 & 2 & $\begin{array}{l}\text { Pecuária } \\
\text { extensiva }\end{array}$ & $\begin{array}{l}\text { Vegetação degrada; a } \\
\text { atividade de } \\
\text { sobrepastoreio tem } \\
\text { provocado } \\
\text { ramoneamento das } \\
\text { cascas das árvores, dos } \\
\text { brotos em germinação } \\
\text { nos ramos e nas } \\
\text { plântulas acarretando o } \\
\text { nanonismo, morte e } \\
\text { aumento dos } \\
\text { espaçamento entre os } \\
\text { indivíduos; } \\
\text { pedregosidade } \\
\text { sobressai na paisagem } \\
\text { variando de 50\% a } \\
100 \% \text {. }\end{array}$ & 1,718 & 0.99 \\
\hline $\begin{array}{l}\text { Planícies } \\
\text { fluviais }\end{array}$ & $\begin{array}{l}\text { Áreas planas } \\
\text { resultantes da } \\
\text { acumulação } \\
\text { fluvial de } \\
\text { sedimentos: } \\
\text { cascalhos, areia } \\
\text { fina e grossa e } \\
\text { argila. Ambiente } \\
\text { de transição } \\
\text { tendendo a } \\
\text { instabilidade. }\end{array}$ & $\begin{array}{l}\text { Neossolo } \\
\text { Flúvico. }\end{array}$ & $\begin{array}{l}\text { Caatinga } \\
\text { arbórea- } \\
\text { arbustiva }\end{array}$ & 5 & 5 & 1 & 5 & 5 & 5 & $\begin{array}{c}3,8 \\
3\end{array}$ & $\begin{array}{c}\text { Área } \\
\text { preservada }\end{array}$ & Não discriminado & 2,247 & 1,28 \\
\hline \multicolumn{13}{|c|}{ Área total } & $\begin{array}{c}175,0 \\
66\end{array}$ & 100 \\
\hline
\end{tabular}

Para a depressão sertaneja parcialmente dissecada o índice obtido foi médio a alto com valores de 2,3 o que é muito preocupante, pois assim como no núcleo do médio Jaguaribe, esse é o sistema de maior expressividade, com área de $147,565 \mathrm{~km}^{2}$ correspondendo a 84, $29 \%$ do núcleo. 
É constituída por um embasamento geológico de rochas metamórficas do pré-cambriano (gnaisses graniticos, granodiorito-gnaisse, biotita-gnaisse) sob um modelado ondulado de 8-15\% de declividade. A vegetação encontra-se inferior a $10 \%$ da área equivalente ao sistema. Os solos são moderadamente rasos com profundidades entre 50 a $100 \mathrm{~cm}$ e erosão laminar moderada a forte.

As cristas residuais apontou um índice 2, configurando assim como o sistema anterior em um nível de degradação/desertificação médio a alto. Sua área é de apenas $1,78 \mathrm{~km}^{2}$ ou seja, 0,99 \% da área total da sub-bacia. Apesar de ser inexpressiva mediante os demais sistemas, é importante a sua preservação por meio da conservação de sua vegetação e do manejo adequado solos. Sua estrutura geológica é composta por rochas metamórficas sob superfície montanhosa com declividade acima dos 45\%. A cobertura vegetacional não difere das demais áreas. Os solos são rasos com profundidade equivalente a 25 a 50 cm e erosão laminar ligeira em cerca de 15 a $30 \%$ da área.

Para as planícies fluviais foi apresentado um índice de 3,83, enquadrando-se ao intervalo médio a baixo nível de degradação/desertificação. É formada por uma superfície de depósito sedimentar com relevo plano. É observado que a cobertura vegetal é de apenas $10 \%$ sob solos mais profundos onde a erosão é não aparente.

Dentre os sistemas ambientais que configuram esse núcleo, as planícies fluviais foram o único sistema a apresentar maior potencialidade ambiental e menor vulnerabilidade, dado ao fato de se constituir atualmente em uma área de preservação. Pelas condições da cobertura vegetal, observa que a área está em um pousio recente, apresentando ainda grande suscetibilidade a degradação/desertificação.

O clima super-úmido é um aspecto que se diferencia do clima semiárido presente nos demais sistemas ambientais de ambos os núcleos. Um dos fatores que podemos associar para a ocorrência dessa diferenciação seria a influência da bacia hidrográfica do Rio São Francisco na região.

\section{CONSIDERAÇÕES FINAIS}

A degradação/desertificação diagnosticada em cada um dos sistemas ambientais de ambos os núcleos, são reflexos do que está ocorrendo em outras áreas do semiárido nordestino. As causas desse desequilíbrio ambiental resultam dos diferentes usos e ocupações pretéritas e atuais desenvolvidas sem que haja um equilíbrio entre a margem de exploração e a capacidade de suporte dos recursos naturais.

As análises permitiram observar que o núcleo da sub-bacia de Santa Rosa apresenta um único sistema ambiental, as cristas residuais o equivalente a $5,9 \mathrm{~km}^{2}$, ou seja, $0,8 \%$ de área com índice de degradação/desertificação médio a alto, seguido da depressão sertaneja aplainada, depressão sertaneja disseca e tabuleiros interiores com degradação moderada abrangendo um total de 
$561.4 \mathrm{~km}^{2}$ o equivalente a $83,1 \%$ do núcleo. Por fim as planícies fluviais se destacando como o único sistema ambiental menos degradado, cujos níveis apontam para uma degradação médio a baixo.

O núcleo da sub-bacia de Itacuruba/Tamanduá possui uma área de $175,066 \mathrm{~km}^{2}$ o que equivale a $37,37 \%$ da área correspondente ao núcleo cearense. Desse valor, cerca de $149,283 \mathrm{~km}^{2}$ ou seja, $85,28 \%$ de terras situadas na depressão sertaneja dissecada e cristas residuais estão submetidas a condições de degradação média alta, seguido da depressão sertaneja aplainada com níveis moderados de degradação/desertificação em uma área de $23.536 \mathrm{~km}^{2}$, cerca de $13,4 \%$ do núcleo. E assim como no núcleo cearense, tem as planícies fluviais como sistema ambiental menos degrado, porém representam apenas $2,247 \mathrm{~km}^{2}$ o que corresponde a $1,28 \%$ de toda a área da sub-bacia.

Podemos concluir que em termos de área degradada a sub-bacia cearense apresenta maior área de terras submetidas a nível moderado de degradação/desertificação. Porém, se consideramos como base os maiores níveis de degradação/desertificação, a sub-bacia pernambucana se destaca com nível médio a alto.

\section{REFERENCIAS}

CEARÁ. Secretaria de Recursos Hídricos, Programa de Ação Estadual de Combate à Desertificação e Mitigação dos Efeitos da Seca, PAE-CE. Fortaleza: Ministério do Meio Ambiente / Secretaria dos Recursos Hídricos, 2010. $375 \mathrm{p}$.

COSTA, L. R. F. Estruturação Geoambiental e Susceptibilidade à Desertificação na Sub-bacia hidrográfica do Riacho Santa Rosa - Ceará. Dissertação (mestrado em Geografia) - Centro de Ciências, Universidade Federal do Ceará, Fortaleza, 2014. 146p.

GUERRA, M.D.F; SOUZA, M.J.N. de; LUSTOSA, J.P.G. A pecuária, o algodão e a desertificação nos sertões do médio Jaguaribe - Ceará/Brasil. Revista Mercator, v. 11, n. 25. Fortaleza: 2002, p. 103-112. Disponível em: <http://www.mercator.ufc.br/index.php/mercator/article/viewArticle/480>. Acesso em: 25/07/2016. MATALLO JUNIOR, H. Indicadores de Desertificação: histórico e perspectivas. Brasília: UNESCO, 2001. 80p. Disponível em: <http://unesdoc.unesco.org/images/0012/001298/129871POR.pdf〉 . Acesso em: 12/08/2016. OLIVEIRA, V. P. V. Indicadores biofísicos de desertificação, Cabo verde/África. Revista Mercator, v. 10 , n. 22. Fortaleza: 2011, p. 147-168. Disponível em: <http://www.mercator.ufc.br/index.php/mercator/article/viewArticle/623> Acesso em: 04/09/2014.

OLIVEIRA, V. P. V. Sistemas ambientais de Santiago - Cabo-Verde (ÁFRICA): Indicadores Biofísicos de Desertificação. In: OLIVEIRA, V. P. V; GOMES, I. G; BAPTISTA, I; RABELO, L. S. Cabo Verde: Análise Socioambiental e Perspectivas para o Desenvolvimento Sustentável em Áreas Semiáridas. Fortaleza: Edições UFC, 2012. 37-64p.

PERNAMBUCO. Secretaria de Ciência, Tecnologia e Meio Ambiente. Programa de Ação Estadual de Pernambuco para o Combate à Desertificação e Mitigação aos Efeitos da Seca, PAE-PE. Recife: CEPE, 2009. 96p. SOUSA, S. C. Avaliação da Degradação/desertificação causada pelo uso e ocupação do solo dos rios São Francisco e Jaguaribe no semiárido nordestino: propostas de recuperação. Tese (Doutorado em Desenvolvimento e Meio ambiente)- Centro de Ciências, Universidade Federal do Ceará, Fortaleza, Fortaleza, 2014. 206p. SOUSA, A. K. O; SOUSA, A. S. M; BEZERRA, C. L. F; OLIVEIRA, V. P. V. Cobertura vegetal e degradação ambiental em núcleos de desertificação no estado do Ceará e Pernambuco. XXXIV Encontro de Iniciação Científica da UFC, Fortaleza. 2015. Disponível em: <http://www.prppg.ufc.br/eu/2015/index.php/trabalhos-aceitos/por-titulo>. Acesso em: 21/12/2015.

\section{AGRADECIMENTOS}

Ao Conselho Nacional de Desenvolvimento Científico e Tecnológico - CNPq pelo apoio no desenvolvimento dessa pesquisa. 